\title{
Luminescence Properties of Eu- and Mg-Codoped Sol-Gel SiO 2 Glasses
}

\author{
Martin O. Onani, ${ }^{1}$ Paul Mushonga, ${ }^{1}$ Lehlohonolo F. Koao, ${ }^{2}$ and Francis B. Dejene ${ }^{2}$ \\ ${ }^{1}$ Department of Chemistry, University of Western Cape, Private Bag X17, Bellville 7535, South Africa \\ ${ }^{2}$ Department of Physics, University of the Free State, Qwaqwa Campus, Private Bag X13, Phuthaditjhaba 9866, South Africa
}

Correspondence should be addressed to Martin O. Onani, monani@uwc.ac.za

Received 26 March 2012; Accepted 18 April 2012

Academic Editors: V. Gurin, L. Y. Khomenkova, W. Łojkowski, W. Lu, K. Miyazawa, and Y. Zhang

Copyright ( $\odot 2012$ Martin O. Onani et al. This is an open access article distributed under the Creative Commons Attribution License, which permits unrestricted use, distribution, and reproduction in any medium, provided the original work is properly cited.

A series of $\mathrm{SiO}_{2}$ nanostructures codoped with $\mathrm{Eu}^{3+} ; \mathrm{Mg}^{2+}$ ions were obtained by a sol-gel method. The gels synthesized by the hydrolysis of $\mathrm{Si}\left(\mathrm{OC}_{2} \mathrm{H}_{5}\right)_{4}, \mathrm{Eu}\left(\mathrm{NO}_{3}\right)_{3} \cdot 6 \mathrm{H}_{2} \mathrm{O}$, and $\mathrm{Mg}\left(\mathrm{NO}_{3}\right)_{2}$ were heated in air at $600^{\circ} \mathrm{C}$ for 2 hours. Firstly, the total amount of $\mathrm{Eu}^{3+}$ ions was varied from 0 to $2.0 \mathrm{~mol} \%$ to investigate the effect of self-damping, while in the second case, the Eu ${ }^{3+}$ ions were kept constant in the experiment at $0.5 \mathrm{~mol} \%$ total doping and $\mathrm{Mg}^{2+}$ ions varied. The samples were characterized by X-ray diffraction, TEM, EDS, and UV lamp-excited luminescence spectroscopy. The Eu ${ }^{3+}$ ions were homogeneously dispersed in the silica and interacting with the small $(1-5 \mathrm{~nm})$ amorphous silica matrix. Strong red emissions located at $614 \mathrm{~nm}$ and $590 \mathrm{~nm}$ for doped and codoped $\mathrm{SiO}_{2}$ were observed from the UV light excitation at room temperature. The composition of around $1.25 \mathrm{~mol}^{2} \mathrm{Eu}^{3+}$ gave highest emission intensity. $\mathrm{SiO}_{2} ; \mathrm{Mg}^{2+}$ ions portray strongly enhanced emissions due to energy transfer from $\mathrm{Mg}^{2+}$ to $\mathrm{Eu}^{3+}$, which is due to radiative recombination. An increase in luminescence intensity was observed as the $\mathrm{Mg}^{2+}$-to-Eu ${ }^{3+}$ ratio increased for the range investigated. The results show $\mathrm{Eu}^{3+}$ ion is located inside or at the surface of disordered $\mathrm{SiO}_{2}$ nanoparticles.

\section{Introduction}

The sol-gel technique that involves the simultaneous hydrolysis and condensation reaction of the metal alkoxide is one of the most common methods of synthesizing silica nanoparticles [1]. It is an efficient technique for the synthesis of phosphors due to the good mixing of starting materials and relatively low reaction temperature resulting in more homogenous products than those obtained by the solidstate reaction synthesis method. Lanthanide ions have been employed as optically active centers due to unique electronic configurations, which result in special spectroscopic properties. Thus, these ions have played prominent role in lighting and light conversion technologies. However, their optical properties, not only depend on the nature of the active ions, but also on the site environment provided by the host lattice. Rare earth ions or lanthanides in a silica host matrix have a wide range of applications in active materials for solid-state lasers, amplifiers, electro-optic devices and sensors because of their well-known fluorescing property [29]. In particular, europium is of great interest since it displays both a sharp luminescence in the orange-red as trivalent ion and a broad band one from UV to blue-green in its divalent configuration. $\mathrm{Eu}^{3+}$ ions are widely used as activators in various materials for their allowed optical transitions of $4 \mathrm{f}-$ $5 \mathrm{~d}$. A strong overlap of the activator $5 \mathrm{~d}$ orbitals with ligand orbital causes high sensitivity of their spectral characteristics to the local environment structure. The luminescence of $\mathrm{Eu}^{3+}$ doped silica is influenced by factors such as the modification of the ligand field around the $\mathrm{Eu}^{3+}$ ions in the silica, presence of hydroxyl ions, energy transfer by cross-relaxation, and the concentration of dopants as well as the preparation process [10]. It is therefore of great interest to distinguish between the luminescence arising from $\mathrm{Eu}^{3+}$-ions and that arising from defect centers in the silica matrix and also investigate the possibility of energy transfer from the matrix to the activators. Thus, the purpose of this paper, firstly, was to study the absorption and luminescent properties 


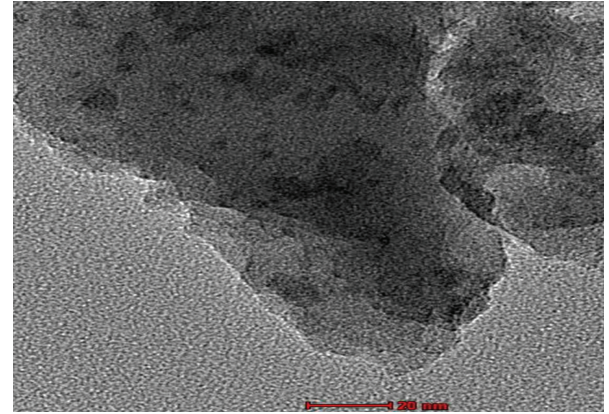

(a)

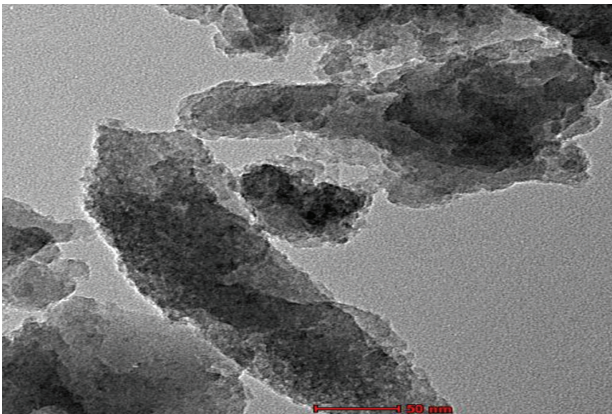

(b)

Figure 1: TEM images of (a) 2 mol\% Eu-doped silica samples; (b) $2 \mathrm{~mol} \% \mathrm{Eu}$ - and $2 \mathrm{~mol} \% \mathrm{Mg}$-doped silica samples at 64000 times magnification.

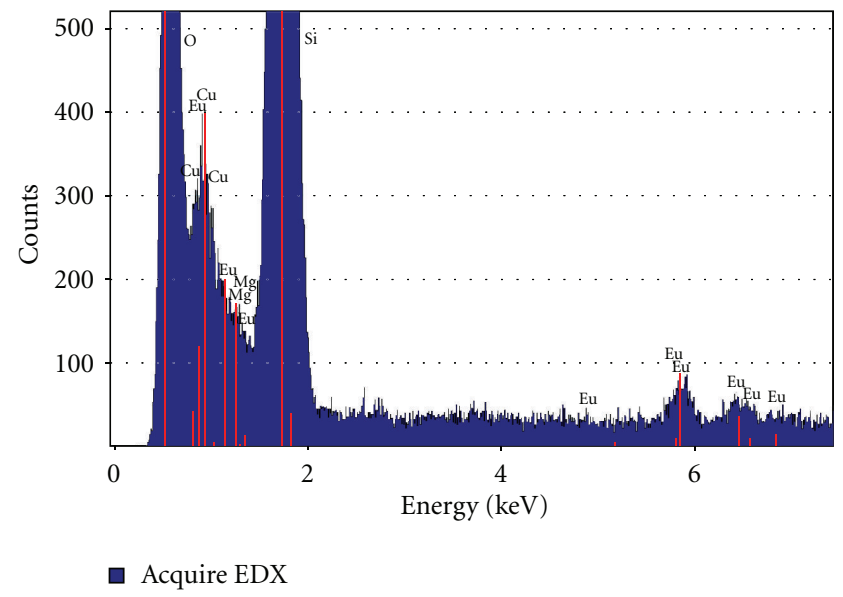

FIGURE 2: EDX spectrum of Mg-codoped xerogels annealed at $600^{\circ} \mathrm{C}$ for $2 \mathrm{~h}$ in air.

by using photoluminescence (PL) spectroscopy of $\mathrm{Eu}^{3+}$ doped and $\mathrm{Eu} / \mathrm{Mg}$-codoped $\mathrm{SiO}_{2}$ glasses made by the sol-gel process. Secondly, the dependence of the PL wavelengths and intensity on the $\mathrm{Mg} / \mathrm{Eu}$ molar ratios was investigated.

\section{Experimental}

2.1. Synthesis of Silica Doped with $\mathrm{Eu}^{3+}$. The procedure followed was modified from the literature [11]. Silica glasses were synthesized by sol-gel using tetraethyl orthosilicate $\left(\mathrm{Si}\left(\mathrm{OC}_{2} \mathrm{H}_{5}\right)_{4}, \mathrm{TEOS}\right)$, ethanol (ETOH), distilled water, nitric acid $\left(\mathrm{HNO}_{3}\right.$, as a catalyst), europium nitrate $\left(\mathrm{Eu}\left(\mathrm{NO}_{3}\right)_{3} \cdot 6 \mathrm{H}_{2} \mathrm{O}\right)$, and magnesium nitrate $\left(\mathrm{Mg}\left(\mathrm{NO}_{3}\right)_{2}\right)$ as material sources. In the preparation of pure silica, TEOS $(10 \mathrm{~mL})$ dissolved in EtOH $(10 \mathrm{~mL})$ was mixed with deionized water $(14 \mathrm{~mL})$. In order to catalyze the hydrolysis and polymerization reaction, concentrated nitric acid $(5 \mathrm{~mL})$ was added, and the mixture was stirred for $24 \mathrm{~h}$ at room temperature. A similar procedure was followed during preparation of a series of europium-doped silica samples. Various masses of europium (iii) nitrate dissolved in ethanol $(5 \mathrm{~mL})$ were added to the foregoing mixture immediately after adding water simultaneously with nitric acid. The solutions were then stirred till gel point. The volume ratio of TEOS, EtOH, water, and $\mathrm{HNO}_{3}$ used was $1: 1: 1.4: 0.5$. The produced gels were dried at room temperature for 2 days. The dried gels were then crushed and later sintered in a furnace at $600^{\circ} \mathrm{C}$ for $2 \mathrm{~h}$ to remove solvent and organic ligands and to obtain full densification. Finally, the powders were recrushed.

2.2. Synthesis of $\mathrm{Eu}^{3+}$ - and $\mathrm{Mg}^{2+}$-Codoped Silica. A similar procedure as above was followed during the preparation of these silica glasses, but during the preparation of $\mathrm{Eu}^{3+}$ and $\mathrm{Mg}^{2+}$-codoped silica, a constant mass of europium (iii) nitrate dissolved in $\mathrm{ETOH}$ and varying masses of magnesium nitrate also dissolved in ETOH were added simultaneously to the foregoing mixture of silica after adding water with nitric acid, and the solutions were stirred till gel point. The dried gels were then again treated as above.

2.3. Characterization of the Particles. The xerogels were annealed at $600^{\circ} \mathrm{C}$ before their characterization. The structure was determined by transmission electron microscopy studies using a Tecnai F20 Field Emission TEM coupled with EDAX. The samples for TEM were prepared by sonicating for 15 minutes their methanol suspensions followed by depositing a drop of the suspension on a standard copper grid coated with a holey carbon film. The photoluminescence (PL) emission spectra were taken on a Cary Eclipse fluorescence spectrophotometer equipped with a monochromatic xenon lamp. Each sample in powder form was loaded into a circular holder and excited with $340 \mathrm{~nm}$ radiation from a pulsed xenon lamp.

\section{Results and Discussion}

Figures 1(a) and 1(b) show the prepared nanosized $\mathrm{Eu}^{3+}$ doped and $\mathrm{Eu}^{3+}$ - and $\mathrm{Mg}^{2+}$-codoped silica xerogels respectively, under HRTEM. The nanosized silica particles had uniform particle sizes of 1 to $5 \mathrm{~nm}$. The presence of $\mathrm{Mg}^{2+}$ causes more particle agglomerations and therefore large particles. 


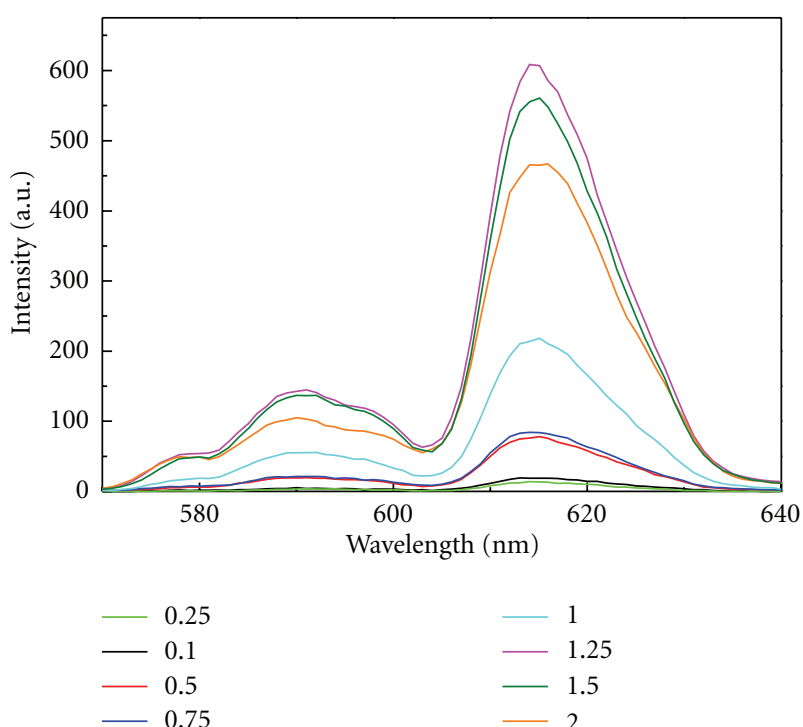

(a)

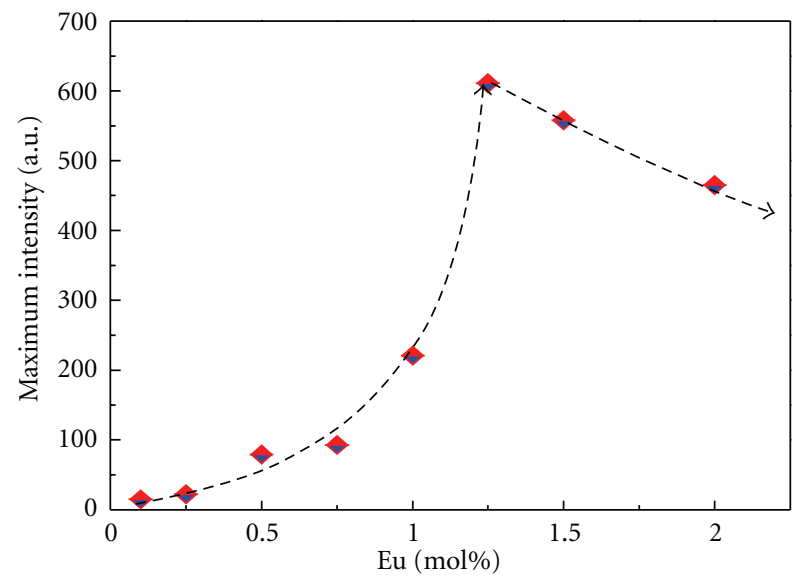

(b)

Figure 3: (a) Photoluminescence emission spectra of Eu-doped silica nanopowders and (b) variation of PL maximum intensity with an increase in Eu concentrations.

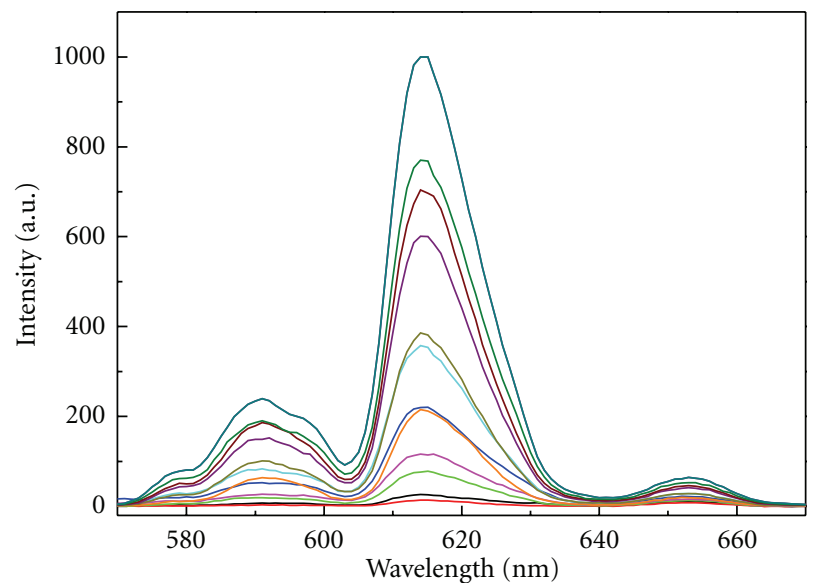

$\mathrm{Mg}: \mathrm{Eu}=$

$\begin{array}{llll}-\mathrm{Mg} 0 \% & -1 & -2 & -4 \\ 0.8 & -1.3 & -2.5 & -10 \\ 1.7 & -1.7 & -3.3 & -20\end{array}$

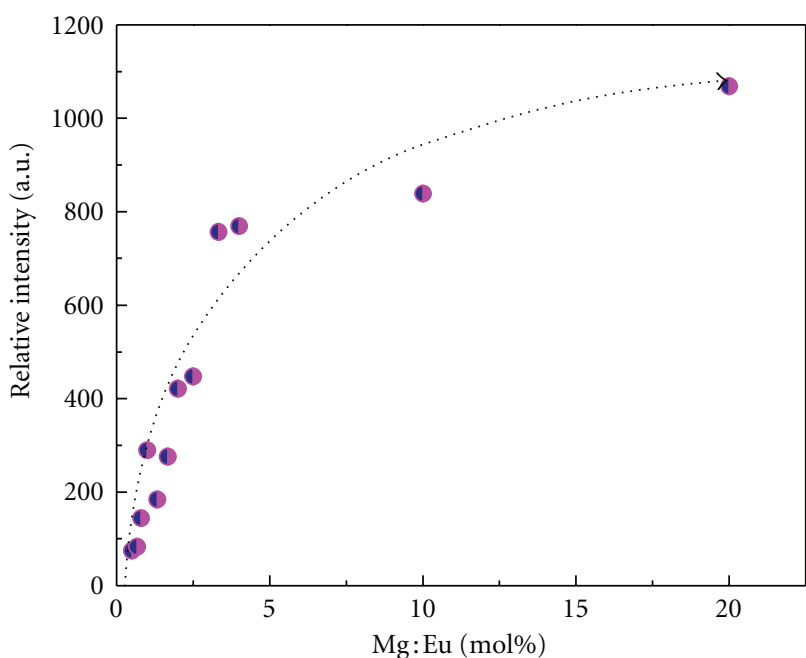

(b)

Figure 4: (a) Mg-codoped silica $(0.5 \mathrm{~mol} \% \mathrm{Eu})$ xerogels annealed at $600^{\circ} \mathrm{C}$ for $2 \mathrm{~h}$ in air and (b) variation of PL maximum intensity with $\mathrm{Mg} / \mathrm{Eu}$ molar ratios.

Figure 2 shows the energy dispersive X-ray spectrum of $2 \mathrm{~mol} \% \mathrm{Mg}^{2+}$-codoped, annealed silica xerogels. The elemental analysis of the nanoparticles confirms the presence of $\mathrm{Si}, \mathrm{O}, \mathrm{Mg}$, and $\mathrm{Eu}$ in the xerogels $(\mathrm{Cu}$ in the EDX spectrum originates from the copper grids). The significantly small counts of $\mathrm{Mg}^{2+}$ and $\mathrm{Eu}^{3+}$ ions are directly indicative of small concentrations of these ions in the samples.

The effects of europium ion concentration at a constant synthesis temperature of $600^{\circ} \mathrm{C}$ on the photoluminescence properties of samples are shown in Figures 3(a) and 3(b).
The PL spectra of the samples excited using a wavelength of $325 \mathrm{~nm}$ show that the emission intensity is related to the concentration of the $\mathrm{Eu}^{3+}$ activator ions. The intensity of the PL peaks was significantly affected by the addition of the europium ions into the sample without any significant change in peak position. The highest luminescence intensity yield of the samples was obtained at a europium concentration of $1.25 \%$, and lower or higher europium contents resulted in a substantial decrease in emission intensity. This decrease in emission intensity indicates the presence of a 
stronger cross-relaxation-induced quenching with smaller interion distance [12].

At higher RE concentrations, most ions reside in cluster due to the insolubility of rare-earth ions in glass which are easily affected by the ambient conditions. Under $325 \mathrm{~nm}$ excitation, the $\mathrm{SiO}_{2}$ : Eu samples emit predominantly in the red domain, that is, $570 \mathrm{~nm}\left({ }^{5} \mathrm{D}_{0} \rightarrow{ }^{7} \mathrm{~F}_{0}\right), 590 \mathrm{~nm}$ $\left({ }^{5} \mathrm{D}_{0} \rightarrow{ }^{7} \mathrm{~F}_{1}\right)$, and $614 \mathrm{~nm}\left({ }^{5} \mathrm{D}_{0} \rightarrow{ }^{7} \mathrm{~F}_{2}\right) \quad[12,13]$. These commonly narrow emissions in red region arise from the $\mathrm{f}-\mathrm{f}$ transitions of the $\mathrm{Eu}^{3+}$ ions. The emission in the vicinity of $590 \mathrm{~nm}$ is due to the magnetic dipole transition ${ }^{5} \mathrm{D}_{0}{ }^{-} \mathrm{F}_{1}$, which is insensitive to site symmetry, while the emission around $610-630 \mathrm{~nm}$ is due to the electric dipole transition of ${ }^{5} \mathrm{D}_{0}-{ }^{7} \mathrm{~F}_{2}$ that is induced by the lack of inversion symmetry at the $\mathrm{Eu}^{3+}$ site [14] and is much stronger than that of the transition to the ${ }^{7} \mathrm{~F}_{1}$ state. The asymmetry ratio of the ${ }^{5} \mathrm{D}_{0}-{ }^{7} \mathrm{~F}_{2}$ to ${ }^{5} \mathrm{D}_{0}-{ }^{7} \mathrm{~F}_{1}$ transitions for the $\mathrm{SiO}_{2}$ : Eu glasses is about 4 and lies well within the range of values usually found in oxide glasses, indicating that the $\mathrm{Eu}^{3+}$ ions occupy low-symmetry sites. The ratio stays approximately constant with an increase in $\mathrm{Eu}^{3+}$ ions up to optimum value, suggesting that the $\mathrm{Eu}^{3+}$ ions are embedded in the random glass network structure of the amorphous silica matrix. ${ }^{5} \mathrm{D}_{0} \rightarrow{ }^{7} \mathrm{~F}_{0}$ is a nondegenerate energy which usually shows large values for FWHM indicating the $\mathrm{Eu}^{3+}$ are accommodated in a continuous distribution in closely similar local sites within the glass. In principle, electric dipoles are Laporte forbidden. However, provided that the site occupied by the $\mathrm{Eu}^{3+}$ does not present a centre of inversion, an odd parity term relaxes the rule in the ligand field Hamiltonian making the transition, ${ }^{5} \mathrm{D}_{0} \rightarrow{ }^{7} \mathrm{~F}_{0}$, permitted $[15,16]$.

Figure 4(a) contains the emission spectra of sol-gel glasses containing $0.5 \mathrm{~mol} \% \mathrm{Eu}^{3+}$ and varying $\mathrm{Mg}$ : Eu mole ratios annealed for $2 \mathrm{~h}$ at $600^{\circ} \mathrm{C}$. The presence of $\mathrm{Mg}$ codopant significantly increases the luminescence intensity. The $\mathrm{Mg}^{2+}$ ions disperse the $\mathrm{Eu}^{3+}$ clusters, enhancing $590 \mathrm{~nm}$ $\left({ }^{5} \mathrm{D}_{0} \rightarrow{ }^{7} \mathrm{~F}_{1}\right)$ and $614 \mathrm{~nm}\left({ }^{5} \mathrm{D}_{0} \rightarrow{ }^{7} \mathrm{~F}_{2}\right)$ emissions due to increased ion-ion distances and decreased cross-relation. The introduction of $\mathrm{Mg}^{2+}$ codopants with different valence from $\mathrm{Eu}^{3+}$ also produces defects, because of charge compensation requirements, resulting in change of energy transfer with the presence of $\mathrm{Mg}^{2+}$ ions. The ratio of increase in intensities of both the 590 and $614 \mathrm{~nm}$ peaks of $\mathrm{Eu}^{3+}$ at higher concentrations of $\mathrm{Mg}^{2+}$ is different from that at lower concentration of $\mathrm{Mg}^{2+}$ ions which indicates a change of surrounding of the $\mathrm{Eu}^{3+}$ ions in the $\mathrm{SiO}_{2}$ lattice at lower concentration of codopant.

An approximately parabolic relation (Figure 4(b)) was observed between the intensity of emission peaks and the molar ratio of $\mathrm{Mg}: \mathrm{Eu}$, which increases significantly as $\mathrm{Mg}^{2+}$ ion concentration increases with a critical value of codopant/RE ratio of $20: 1$. Previously aluminium [17] has been shown to be more efficient in enhancing luminescence of dopants in materials such as $\mathrm{Tb}^{3+}[18]$ and thus became the standard codopant used by different research groups [19] in the phosphor field. Now, we see other elements such as Eu and $\mathrm{Mg}$ showing similar properties.

\section{Conclusions}

$\mathrm{Eu}^{3+}$-doped and $\mathrm{Eu}^{3+}$ - and $\mathrm{Mg}^{2+}$-codoped silica phosphor powders were successfully synthesized by the sol-gel process. The PL results of the doped and codoped silica glasses showed predominantly red emission peaks at 570,590 , and $614 \mathrm{~nm}$. The origin of these three peaks is ascribed to the crystal field splitting of the $4 \mathrm{f}$ levels of $\mathrm{Eu}^{3+}$ ion. While an increase in luminescence intensity was observed as the $\mathrm{Mg}^{2+}$-to- $\mathrm{Eu}^{3+}$ ratio increased for the range investigated, significant luminescence enhancement was observed for codopant: Eu ratio of $20: 1$. This enhanced photoluminescence was attributed to two possible factors, the first being an energy transfer from the $\mathrm{SiO}_{2}: \mathrm{Mg}$ nanostructures resulting in enhanced emission from $\mathrm{Eu}^{3+}$. The second factor was that the $\mathrm{Mg}^{2+}$ ion disperses the $\mathrm{Eu}^{3+}$ clusters, enhancing the $590 \mathrm{~nm}\left({ }^{5} \mathrm{D}_{0} \rightarrow{ }^{7} \mathrm{~F}_{1}\right)$ and $614 \mathrm{~nm}\left({ }^{5} \mathrm{D}_{0} \rightarrow{ }^{7} \mathrm{~F}_{2}\right)$ emissions as a result of the increased ion-ion distances and decreased cross-relation.

\section{Acknowledgments}

The authors would like to acknowledge the National Research Foundation, University of the Free State, University of the Western Cape, and the Organization for the Prohibition of Chemical Weapons for financial support. They are also grateful to the people currently of Centre for Microscopy at UFS and at UWC for EDS and HRTEM measurements.

\section{References}

[1] L. L. Hench and J. K. West, "The sol-gel process," Chemical Reviews, vol. 90, no. 1, pp. 33-72, 1990.

[2] A. P. Golovina, V. K. Runov, and N. B. Zorov, "Chemical luminescence analysis of inorganic substances," in Ferrites. Transitions Elements Luminescence, vol. 47 of Structure \& Bonding, pp. 53-119, 1981.

[3] H. Eilers and B. M. Tissue, "Laser spectroscopy of nanocrystalline $\mathrm{Eu}_{2} \mathrm{O}_{3}$ and $\mathrm{Eu}^{3+}: \mathrm{Y}_{2} \mathrm{O}_{3}$," Chemical Physics Letters, vol. 251, no. 1-2, pp. 74-78, 1996.

[4] R. S. Meltzer, S. P. Feofilov, B. Tissue, and H. B. Yuan, "Dependence of fluorescence lifetimes of $\mathrm{Y}_{2} \mathrm{O}_{3}: \mathrm{Eu}^{3+}$ nanoparticles on the surrounding medium," Physical Review B, vol. 60, no. 20, pp. R14012-R14015, 1999.

[5] T. Igarashi, M. Ihara, T. Kusunoki, K. Ohno, T. Isobe, and M. Senna, "Relationship between optical properties and crystallinity of nanometer $\mathrm{Y}_{2} \mathrm{O}_{3}$ : Eu phosphor," Applied Physics Letters, vol. 76, no. 12, pp. 1549-1551, 2000.

[6] G. Wakefield, E. Holland, P. J. Dobson, and J. L. Hutchison, "Luminescence properties of nanocrystalline $\mathrm{Y}_{2} \mathrm{O}_{3}$ :Eu," Advanced Materials, vol. 13, no. 20, pp. 1557-1560, 2001.

[7] H. Peng, H. Song, B. Chen et al., "Temperature dependence of luminescent spectra and dynamics in nanocrystalline $\mathrm{Y}_{2} \mathrm{O}_{3}: \mathrm{Eu}^{3+}$," Journal of Chemical Physics, vol. 118, no. 7, pp. 3277-3282, 2003.

[8] M. Yu, J. Lin, J. Fu, and Y. C. Han, "Sol-gel fabrication, patterning and photoluminescent properties of $\mathrm{LaPO}_{4}: \mathrm{Ce}^{3+}$, $\mathrm{Tb}^{3+}$ nanocrystalline thin films," Chemical Physics Letters, vol. 371, no. 1-2, pp. 178-183, 2003. 
[9] K. A. Gschneidner Jr., J.-C. Bünzli, and V. K. Pecharsky, "Preface," Handbook on the Physics and Chemistry of Rare Earths, vol. 39, pp. 5-8, 2009.

[10] A. J. Silversmith, D. M. Boye, R. E. Anderman, and K. S. Brewer, "Fluorescence line narrowing and decay dynamics in sol-gel glasses containing Eu ${ }^{3+}$," Journal of Luminescence, vol. 94-95, pp. 275-278, 2001.

[11] L. F. Koao, H. C. Swart, E. Coetsee, M.-M. Biggs, and F. B. Dejene, "The effect of $\mathrm{Mg}^{2+}$ ions on the photoluminescence of $\mathrm{Ce}^{3+}$-doped silica," Physica B, vol. 404, no. 22, pp. 4499-4503, 2009.

[12] X.-C. Jiang, C.-H. Yan, L.-D. Sun, Z.-G. Wei, and C.-S. Liao, "Hydrothermal homogeneous urea precipitation of hexagonal $\mathrm{YBO}_{3}: \mathrm{Eu}^{3+}$ nanocrystals with improved luminescent properties," Journal of Solid State Chemistry, vol. 175, no. 2, pp. 245251, 2003.

[13] R. Reisfeld, A. Patra, G. Panczer, and M. Gaft, "Spectroscopic properties of cerium in sol-gel glasses," Optical Materials, vol. 13, no. 1, pp. 81-88, 1999.

[14] C. Guo, F. Gao, Y. Xu, L. Liang, F.G. Shi, and B. Yan, "Efficient red phosphors $\mathrm{Na}_{5} \mathrm{Ln}\left(\mathrm{MoO}_{4}\right)_{4}: \mathrm{Eu}^{3+}(\mathrm{Ln}=\mathrm{La}, \mathrm{Gd}$ and $\mathrm{Y})$ for white LEDs ," Journal of Physics D, vol. 42, Article ID 095407, 2009.

[15] L. D. Carlos, R. A. Sá Ferreira, V. de Zea Bermudez, C. Molina, L. A. Bueno, and S. J. L. Ribeiro, "White light emission of $\mathrm{Eu}^{3+}-$ based hybrid xerogels," Physical Review B, vol. 60, no. 14, pp. 10042-10053, 1999.

[16] O. L. Malta and L. D. Carlos, "Intensities of $4 \mathrm{f}-4 \mathrm{f}$ transitions in glass materials," Quimica Nova, vol. 26, no. 6, pp. 889-895, 2003.

[17] A. J. Silversmith, N. T. T. Nguyen, B. W. Sullivan, D. M. Boye, C. Ortiz, and K. R. Hoffman, "Rare-earth ion distribution in sol-gel glasses co-doped with $\mathrm{Al}^{3+}$," Journal of Luminescence, vol. 128, no. 5-6, pp. 931-933, 2008.

[18] D. M. Boye, A. J. Silversmith, T. N. Nguyen, and K. R. Hoffman, "Effects of rehydration on $\mathrm{Tb}^{3+}$ spectroscopy in solgel glasses," Journal of Non-Crystalline Solids, vol. 353, no. 2425, pp. 2350-2354, 2007.

[19] A. Monteil, S. Chaussedent, G. Alombert-Goget et al., "Clustering of rare earth in glasses, aluminum effect: experiments and modeling," Journal of Non-Crystalline Solids, vol. 348, pp. 44-50, 2004. 

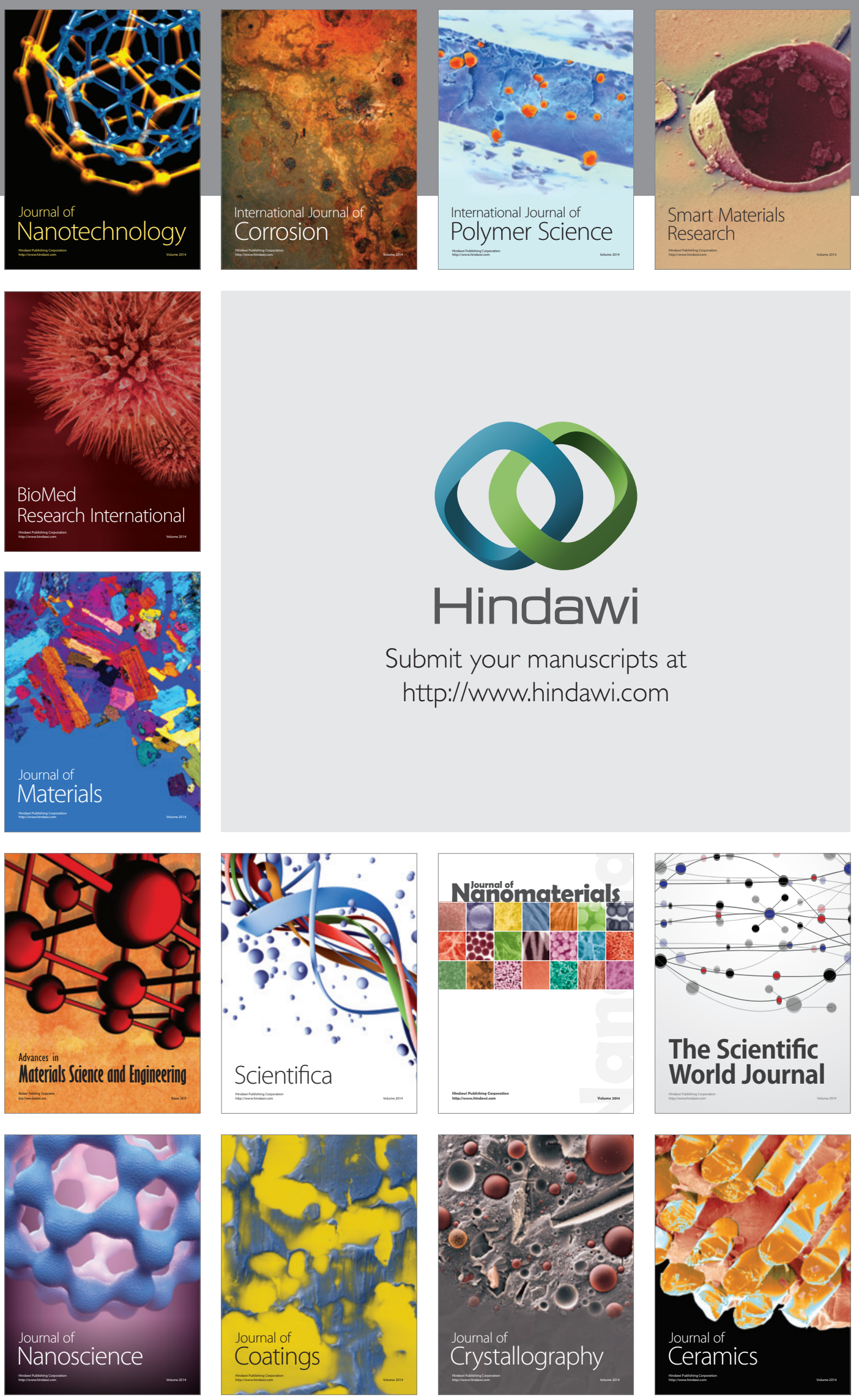

The Scientific World Journal

Submit your manuscripts at

http://www.hindawi.com

\section{World Journal}

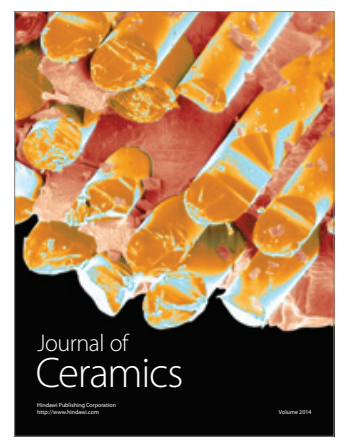

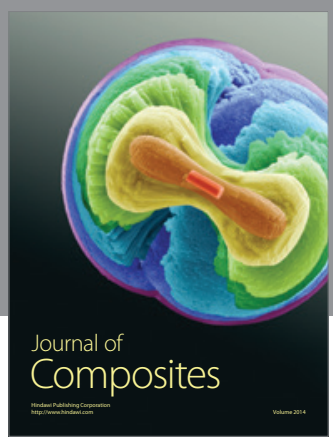
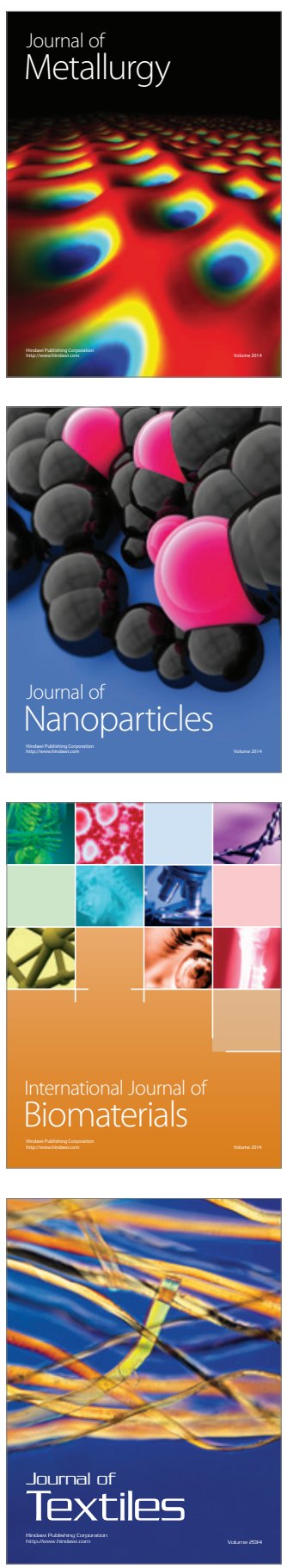